What is significant about this proof is that it relies entirely on the basics - the Pythagorean theorem, the unit circle, the definition of sine and cosine, the definition of the radian measure of an angle, the distance formula, and the power rule.

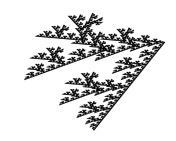

\section{A Response to Clunn's Axioms of Morality}

\section{J R Miller}

DOI: $10.33014 /$ issn.2640-5652.3.1.miller.1

This article offers a brief critique of Clunn's foundationalism which grounds moral decision making in what he calls the three fundamental axioms of existence, consciousness, and identity (Clunn, 2019). It shows how his commitment to neo-Platonism, or possibly pantheism, creates at least three incoherencies wherein a priori is a posteriori, individuality is an illusion, and objective morality is subjective. For Clunn's moral philosophy to offer practical value, these internal conflicts must be resolved.

\section{Introduction}

In his article, Axioms of Morality, Clunn argues that morality is an a priori truth that is objectively known to every person. He believes that the fundamental axioms of existence, consciousness and identity make life itself the ultimate objective standard for each person's subjective moral choices. Therefore, as a general rule, any moral choice which benefits life in general is a moral good. Any moral choice which hurts life in general is a moral evil. Clunn rejects selfishness and utilitarianism as viable methods for choosing what is good. Instead, he argues that our individual choices must be guided by what he considers the four cardinal virtues defined by history: justice, prudence, temperance and courage.

Finding an objective ground for moral good is a daunting task for any philosopher. And while Clunn's three axioms are important, the grounding for his overarching moral philosophy is problematic. For Clunn, every person shares in the same a priori universal consciousness which is a nonreductive emergent property of the biological structures that define humanness. If it is true that existence, consciousness and identity exist a priori to human life in some form of neo-Platonic realm- or possibly in a pantheistic universe-at least three internal conflicts arise.

\section{Conflict \#1: A Priori is A Posteriori}

Clunn leans heavily on Ayn Rand for defining his axioms but departs from Rand who taught that consciousness and morality are a posteriori. This distinction is critical for Clunn as he hopes to sustain his commitment to both objective morality and free will. He writes, "At the end of the day, morality is about free will, choices, and decisions. These things all exist within our consciousness (45)." Here is where the incoherence first manifests. By definition, a priori means that morality must exist independent of any person's experience. Yet, Clunn also presumes that morality exists through the exercise of one's free will. Given these claims, morality must also be a posteriori because it depends upon how each individual person exercises their free will. Clunn's presupposition of a priori morality may be preserved if he assumes free will is also an expression of the a priori universal consciousness. However, this assumption leads to a second conflict for how Clunn defines identity.

\section{Conflict \#2: Individuality is an Illusion}

For Clunn, consciousness is not a property of personhood, but an emergent property of the physical realm that existed before any individual. That is to say, all humans share in the one nonreductive a priori universal consciousness. At the same time, Clunn argues that the term "I" is an expression of rational thought which establishes one's specific identity within the universal consciousnesses. But even if "I" establishes my personal existence, it remains an existence only within the larger axiom of existence. It seems to follow from Clunn's own definitions that the perception of individuality, and by extension free choice, is only an illusion. This creates at least one significant internal conflicts for Clunn's axioms.

Clunn argues that the consequences of our decisions are experienced only within the realm of personal consciousness, which no other person can observe. In contrast, Clunn says that we can observe existence. Yet, for Clunn, morality does not manifest in the axiom of existence. However, if each person's consciousness is a shared a priori reality, how is it beyond my powers of observation? If I can have awareness of my own consciousness, and that consciousness is tied to the universal, then by definition I must also have access to understanding the consciousness of others because they too are tied to the same universal axiom. Even more, if consciousness is an emergent property of existence, how does it remain independent of existence as it relates to morality? This incoherence leads to 
the final issue addressed herein regarding Clunn's claim that objective morality exists.

\section{Conflict \#3: Objective Morality is Subjective}

According to Clunn, the goal of his work is to establish a simple way for people to make moral choices that do not rely on some deeply esoteric philosophy. While this goal is laudable, Clunn's claim to objective moral reality remains frustratingly subjective. Even if we grant that consciousness is a fundamental axiom and that morality exists in some neo-Platonic form, this says nothing about how we should evince this unobservable moral realm. How does Clunn's foundationalism solve the is/ought problem? Clunn concedes that even given his belief in an objective moral realm, "there is not a physical imperative to adhere to it (45)." In the end, Clunn's morality seems like a philosophically complex version of the equally impractical moral trope, 'follow your heart.'

Clunn's claim to objective morality ends in a confusing subjectivity. He writes, "I don't prescribe here any specific actions that a human should take to be moral or immoral. Specific actions can and should be subjective to each individual (44-45)." Now to suggest that morality is objective, but all individual actions are subjective and beyond judgement from others only begs the question about what it means to value life? Clunn is aware that his dualist morality leads to moral confusion and leaves open the argument that 'might makes right.' To evade this looming problem, he asserts that consciousness is an emergent function of existence, but he fails to show how this claim logically undermines the 'might makes right' philosophy. Even worse, Clunn admits that taking life is unjust, but believes his own willingness to take a human life is virtuous. He writes, "I have no qualms, nor does my morality, with taking a life if that life is deciding to destroy other lives (45)." But if, as he claims, there is no basis to judge the conscientious free moral choice of another person, on what foundation-outside of his own subjective opinion-does Clunn decide it is right to end the life of another person? Maybe the person Clunn chose to kill had a reason within their own mind that justified their choice to take a life. Maybe they killed in the hope that their act would serve the higher virtue of protecting lives. On what ground does Clunn judge their act as an evil? And what if my subjective morality tells me that Clunn's choice to kill is wrong? What would keep me from continuing this same cycle of violence? How can Clunn claim to preserve the general principle of life, without protecting the individual life of each person?

\section{Conclusion}

This article offered a brief critique of Clunn's foundationalism which grounds moral decision making in what he calls the three fundamental axioms of existence, consciousness, and identity. It showed how his commitment to neo-Platonism, or possibly pantheism, creates at least three incoherencies wherein a priori is a posteriori, individuality is an illusion, and objective morality is subjective. For Clunn's moral philosophy to offer practical value, these internal conflicts must be resolved.

Clunn, M (2019). "Axioms of Morality". In: Communications of the Blyth Institute 1.1, pp. 43-45. DOI: 10.33014 / issn.2640-5652.1.1.clunn.1.

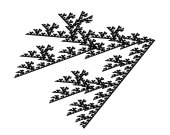

\section{Is Information Content a Single, Static Quantity?}

Jorge Fernandez

DOI: 10.33014/issn.2640-5652.3.1.fernandez.1

Information is instinctively and commonly regarded as a single, static entity. For example, upon learning that 'her name is Susan' we would say that we have 'acquired information'. Taken that way, an instance of information naturally leads to a single, static quantity of information. Thus, if asked how much information is contained in learning that a flip of a fair coin yielded a 'heads', the typical answer is ' 1 bit of information' $\left(-\log _{2}\left(\frac{1}{2}\right)=1\right.$ bit $)$.

Seasoned information theorists are, of course, aware that there is more to it than that. Yet even those individuals usually operate within a paradigm that is most often not as comprehensive as it needs to be to address the full information picture. Thus, ' 1 bit' merely indicates the number of possible states $\left(2^{1}=2\right.$ states $)$. Alone, this number is indifferent regarding deeper, significant aspects of information such as meaning.

There is an attribute about information that is even more fundamental than those considerations. I am specifically referring to the fact that before information may be measured it must first manifest as a specific kind of information, and that manifestation always occurs within a fixed context. If any critical element of the context is changed, the information that is 